\title{
Formação de Professores e Educação Ambiental: desafios e conquistas no contexto imposto pela Pandemia de Covid-19
}

\section{Teacher preparation and Environmental Education: challenges and achievements in the context imposed by the Covid-19 Pandemic}

\author{
Rafael Alberto Moretto (rmoretto@usp.br) \\ Professor do Departamento de Educação, Informação e Comunicação (DEDIC) da Faculdade de \\ Filosofia, Ciências e Letras de Ribeirão Preto (FFCLRP), Universidade de São Paulo (USP)
}

Joyce Ingrid de Lima (joycelima@usp.br)

Mestranda pelo Programa de Pós-graduação em Educação da Faculdade de Filosofia, Ciências e Letras de Ribeirão Preto (FFCLRP), Universidade de São Paulo (USP)

Maria Vitória Guidorzi (guidorzim@usp.br)

Graduanda em Química pela Faculdade de Filosofia, Ciências e Letras de Ribeirão Preto (FFCLRP), Universidade de São Paulo (USP)

Heloísa Canato Affonso (helocanato@usp.br)

Graduanda em Química pela Faculdade de Filosofia, Ciências e Letras de Ribeirão Preto (FFCLRP), Universidade de São Paulo (USP)

Resumo: O presente trabalho é resultado de um projeto de extensão do Departamento de Educação, Informação e Comunicação da Faculdade e Filosofia, Ciências e Letras de Ribeirão Preto, Universidade de São Paulo, inicialmente planejado para ser desenvolvido de forma presencial, mas que fora adaptado para o formato remoto, devido ao contexto da pandemia de Covid-19. Como objetivo geral, visamos promover cursos de formação para professores e licenciandos de forma online, discutindo a temática da Educação Ambiental de maneira interdisciplinar e integrada, apresentando assuntos, estratégias metodológicas e ações que podem ser transpostas, contextualizadas e trabalhadas em sala de aula com as diferentes faixas etárias. Foram 17 encontros virtuais no formato de live, transmitidos pelo YouTube e divididos em três módulos temáticos, entre os meses de junho e outubro de 2020, contando com a participação de 28 palestrantes especialistas em cada uma das temáticas apresentadas. Nosso público-alvo foi composto principalmente por alunos de Graduação e professores já formados que atuam na Educação Básica. Conseguimos atingir um total de mais de 9650 pessoas de todo o Brasil, número muito superior ao inicialmente previsto, caso o projeto tivesse sido desenvolvido de maneira presencial, cujo alcance seria muito menor e restrito.

Palavras-chave: Educação ambiental crítica; Formação inicial e continuada; Ensino remoto. 
Abstract: The present work is the result of an extension project of the Departmento de Educação, Informação e Comunicação of the Faculdade de Filosofia, Ciências e Letras de Ribeirão Preto, Universidade de São Paulo, initially planned to be developed in person, but had to be adapted for the remote format, due to the context of the Covid-19 pandemic. The general objective was to promote online training courses for teachers and undergraduate students, discussing the theme of Environmental Education in an interdisciplinary and integrated way, presenting subjects, methodological strategies and actions that can be transposed, contextualized and worked in the classroom with different age groups. There were 17 virtual meetings (lives), transmitted by YouTube and divided into three thematic modules, between the months of June and October 2020, with the participation of 28 speakers experts in each of the themes presented. We reached more than 9650 people from all over country, the majority of undergraduate students and teachers who work in Basic Education, a number much higher than initially planned, if the project had been developed in person, which would be very smaller and more restricted.

Keywords: Critical environmental education; Initial and continuing training; Remote teaching.

\section{INTRODUÇÃO}

A importância da Educação Ambiental (EA) é cada vez mais evidente na sociedade. Em um país continental, com uma natureza exuberante e riquíssima como o Brasil, esta política possui valor inestimável e deve ser encarada como base do sistema educacional brasileiro. Os valores sociais são os pilares da educação ambiental, buscando a valorização de uma sociedade que sabe conciliar evolução tecnológica com a demanda de consumo, sem afetar o meio ambiente. A proposta é bem clara: um mundo que possa consumir sem destruir a natureza e seus recursos cada vez mais escassos. O desenvolvimento humano deve respeitar o ambiente em que está inserido (MORETTO, 2018).

De acordo com a Lei Federal no 9.795/99, a Política Nacional de Educação Ambiental visa à construção de uma sociedade ambientalmente equilibrada, fundada nos princípios da liberdade, igualdade, solidariedade, democracia, justiça social, responsabilidade e sustentabilidade. A EA é um direito de todos, sendo um componente essencial e permanente da educação nacional, que deve ser exercida de forma articulada em todos os níveis e modalidades de ensino.

De acordo com os Parâmetros Curriculares Nacionais (1999), a EA é um tema transversal, que deve ser abordado em diferentes disciplinas do currículo escolar, de Recebido em: 18/01/2021

Aceito em: 24/02/2021 
Edição Especial: I SSAPEC - Simpósio Sul-Americano de Pesquisa em Ensino de Ciências

ISSN: 2595- $4520 \quad$ Vol. 4, n. 3. 2021

maneira interdisciplinar e integrada, buscando a formação da consciência ecológica e mudança atitudinal no aluno, que deve se enxergar como parte do processo e responsável direto pela temática ambiental.

Mais recentemente, com a Base Nacional Comum Curricular (2018), a EA visa à promoção do desenvolvimento do saber ambiental, do raciocínio crítico e da noção das relações entre Ciência, Tecnologia, Sociedade e Ambiente, indispensável à participação da cidadania na tomada de decisões, por meio de articulações entre fenômenos naturais e sociais que podem ser estudados, analisados, investigados e discutidos de forma integrada e relacional.

Várias dificuldades podem surgir quando queremos trabalhar de uma maneira interdisciplinar, muitos apontam como obstáculo a formação fragmentada, linear e descontextualizada dos profissionais que trabalham na educação, além das condições de trabalho a que estão submetidos, como organização de grades curriculares, falta da manutenção dos equipamentos, falta de motivação própria, entre tantos outros fatores. Ensinar de maneira interdisciplinar é um desafio, primeiramente, por desconstruir o papel do professor transmissor do conteúdo, o professor deve ser reflexivo, colaborativo, atuar como mediador da troca de ideias e conhecimentos entre os alunos.

O professor é o resultado dos seus saberes oriundos da formação profissional, dos saberes das disciplinas, dos currículos e da experiência (TARDIF, 2002). Como dizia Paulo Freire (1991, p. 58): "Ninguém nasce professor ou marcado para ser professor. A gente se forma como educador permanentemente, na prática e na reflexão sobre a prática". A formação continuada é parte do desenvolvimento profissional e acontece ao longo do exercício docente, que possibilita um novo sentido à prática pedagógica, permitindo contextualizar novas circunstâncias e ressignificar a atuação do professor (NÓVOA; FINGER, 2010; MENDES, 2013; NOGUEIRA; PAVANELLO; OLIVEIRA, 2014).

A formação continuada não coloca os professores como ouvintes passivos que precisam ser 'reciclados' ou 'capacitados', pelo contrário, o intuito é priorizar a investigação da própria prática docente ou de temas relacionados aos interesses de seu próprio contexto escolar e pessoal (LASTÓRIA; ASSOLINI, 2010). Além disso, permite a aproximação entre os processos de ordem teórica e experiências práticas vividas no contexto da escola, contribuindo, assim, de forma decisiva para o Recebido em: 18/01/2021

Aceito em: 24/02/2021 
Edição Especial: I SSAPEC - Simpósio Sul-Americano de Pesquisa em Ensino de Ciências ISSN: 2595- $4520 \quad$ Vol. 4, n. 3. 2021

desenvolvimento de competências e conhecimento profissional do professor, além de aprimorar as capacidades reflexivas sobre a própria prática docente (IMBERNÓN, 2010; SANTANA; ROTHEN, 2015).

Nesse sentido, foi idealizado um projeto de extensão de uma Universidade pública do Estado de São Paulo, com o objetivo de oferecer cursos de formação inicial e continuada, para professores atuantes na Rede Básica de Ensino e para licenciandos em formação, abordando as diferentes temáticas da EA de maneira interdisciplinar e integrada, apresentando estratégias metodológicas e ações que podem ser aplicadas nas salas de aula, bem como explorando suas potencialidades pedagógicas e motivacionais.

\section{METODOLOGIA}

Em parceria com a Diretoria Regional de Ensino de Ribeirão Preto e com a Secretaria Municipal de Educação de Ribeirão Preto, planejamos 15 encontros de formação, com grupos de 40 a 60 professores cada, entre os meses de março novembro de 2020, além de 5 encontros destinados exclusivamente para professores em formação, graduandos dos cursos de Licenciatura da Faculdade de Filosofia, Ciências e Letras de Ribeirão Preto, Universidade de São Paulo, no mesmo período. As datas já estavam estabelecidas, assim como as temáticas e os palestrantes convidados para cada um dos 20 encontros previstos, mas, devido à situação imposta pela pandemia de Covid-19, todo nosso planejamento se tornou inviável, já que os encontros presenciais foram impedidos de acontecer, por uma questão de saúde pública.

Depois de muitas discussões entre os membros da equipe, todas as ações foram replanejadas e, nesse contexto de excepcionalidade, decidimos adaptar as formações para o formato remoto. Para divulgar os temas e encontros, foram criadas redes sociais, fizemos um novo planejamento de datas, temas e convidados, e passamos a oferecer encontros semanais na forma de lives pelo YouTube, todas as quartas-feiras, das 17:30h às 19h, utilizando o Stream Yard como plataforma de transmissão.

As formações foram separadas em três módulos: "Diálogos sobre Biodiversidade", "Diálogos sobre Sustentabilidade" e "Diálogos sobre Educação Ambiental. Foram 5 encontros para cada um dos dois primeiros módulos e 7 encontros para o terceiro módulo, sendo que cada encontro teve duração média de 1 hora e meia e contou com a participação de um ou mais palestrante especialista no tema. Durante a Recebido em: 18/01/2021 
Edição Especial: I SSAPEC - Simpósio Sul-Americano de Pesquisa em Ensino de Ciências

live, foi disponibilizado pelo chat do YouTube um formulário de inscrição, gerado no Google Form, no qual todos os expectadores que preenchessem durante a realização do encontro, receberiam certificado de participação no evento.

\section{RESULTADOS E DISCUSSÃO}

Foram realizados 17 encontros remotos entre os meses de junho e outubro de 2020, cada um com uma temática diferente e com a participação de um ou mais palestrantes especialistas no assunto. Ao todo, 28 palestrantes contribuíram com o projeto, a maioria composta por professores de diversas Universidades do país. Quanto ao total de espectadores, estamos perto de atingir as 10 mil visualizações das lives.

Além do grande alcance nos vídeos dos encontros, conseguimos atingir um público bastante significativo também por meio das redes sociais. Atualmente, nossa página no Facebook (https://www.facebook.com/FormacaoodeProfessores EdAmbiental/) tem mais de 1.200 curtidas, o perfil no Instagram (https://www.instagram. com/formacaoedambientalusp/?hl=pt) conta com cerca de 400 seguidores, nosso canal do YouTube (https://www.youtube.com/channel/UCjNi9H DwPR8SKCIVHJbeHcA/vídeos) tem mais de 1.000 inscritos e desenvolvemos um site (https://formacao-em-educacao-ambiental.webnode.com/) para disponibilizar os conteúdos abordados e materiais complementares.

Com o intuito de sistematizar as informações, as Tabelas 1, 2 e 3 apresentam os temas abordados em cada encontro dos três módulos do projeto, os palestrantes convidados e o número de visualizações dos vídeos no YouTube até o dia 12 de janeiro de 2021.

Tabela 1. Encontros remotos do módulo I: "Diálogos sobre Biodiversidade"

\begin{tabular}{c|c|c|c}
\hline Datas & Tema & Palestrantes & $\begin{array}{c}\text { Visualizações } \\
\text { no YouTube }\end{array}$ \\
\hline $\mathbf{0 3 / 0 6 / 2 0 2 0}$ & $\begin{array}{c}\text { "Biodiversidade, } \\
\text { bem-estar humano e } \\
\text { o ensino de } \\
\text { Zoologia" }\end{array}$ & $\begin{array}{c}\text { Prof. Dr. Fábio de } \\
\text { Oliveira Roque e Prof. } \\
\text { Dr. Adolfo Ricardo Calor }\end{array}$ & 1.083 \\
\hline
\end{tabular}


Edição Especial: I SSAPEC - Simpósio Sul-Americano de Pesquisa em Ensino de Ciências

\begin{abstract}
\begin{tabular}{|c|c|c|c|}
\hline $10 / 06 / 2020$ & $\begin{array}{l}\text { "O verde urbano e } \\
\text { suas funções na } \\
\text { saúde pública do } \\
\text { munícipio" }\end{array}$ & $\begin{array}{c}\text { Prof. }^{\text {a }} \text { Dr. }{ }^{\text {a }} \text { Clarice Sumi } \\
\text { Kawasaki e MSc. Perci } \\
\text { Guzzo }\end{array}$ & 628 \\
\hline $17 / 06 / 2020$ & $\begin{array}{l}\text { "Biodiversidade e } \\
\text { ensino de biologia } \\
\text { nas BIONAS" }\end{array}$ & $\begin{array}{c}\text { Prof. }^{\text {a }} \text { Dr. } \\
\text { Kawasaki e Prof. Dr. } \\
\text { Danilo Seithi Kato }\end{array}$ & 622 \\
\hline $24 / 06 / 2020$ & $\begin{array}{l}\text { "Biodiversidade, } \\
\text { conservação e } \\
\text { educação" }\end{array}$ & $\begin{array}{c}\text { Prof. Dr. Rafael Alberto } \\
\text { Moretto }\end{array}$ & 475 \\
\hline $01 / 07 / 2020$ & $\begin{array}{l}\text { "Biodiversidade em } \\
\text { sala de aula: } \\
\text { caminhos para a } \\
\text { formação cidadã" }\end{array}$ & $\begin{array}{l}\text { MSc. Anne Caroline de } \\
\text { Freitas e MSc. Ana Elisa } \\
\text { Montebelli Motta }\end{array}$ & 648 \\
\hline
\end{tabular}
Biodiversidade e os seus diversos desdobramentos dentro da EA e do ensino. Foram 5 encontros dentro do eixo temático "Diálogos sobre Biodiversidade", que versaram sobre o assunto sob diferentes perspectivas. No primeiro deles, o Prof. Dr. Adolfo Calor e o Prof. Dr. Fábio Roque fizeram uma discussão sobre "Biodiversidade, bem-estar humano e ensino de Zoologia", relacionando não só a importância do tema no ensino de Ciências e Biologia, mais especificamente com um olhar sobre a Zoologia, mas também ressaltando a importância da preservação das espécies e do contato com a Biodiversidade para o nosso próprio bem-estar físico e mental.

No segundo encontro do módulo, a Prof. ${ }^{a}$ Dr. ${ }^{a}$ Clarice Sumi Kawasaki e o MSc. Perci Guzzo discutiram a importância da preservação das áreas verdes urbanas não só para a manutenção da Biodiversidade, mas também como uma questão de saúde pública dos municípios, com ótimas sugestões de leitura e exemplos, além de abordarem a possibilidade de utilização de praças e parques como espaços não formais de ensino para a promoção da EA.
\end{abstract}

No terceiro encontro, intitulado "Biodiversidade e ensino de biologia nas BIONAS", o Prof. Dr. Danilo Kato, contando com a mediação da Prof. a Dr. ${ }^{a}$ Clarice Sumi Kawasaki, apresentou o resultado do projeto BIONAS, com relatos das Recebido em: 18/01/2021

Aceito em: 24/02/2021 
Edição Especial: I SSAPEC - Simpósio Sul-Americano de Pesquisa em Ensino de Ciências

ISSN: 2595- $4520 \quad$ Vol. 4, n. 3. 2021

bionarrativas sociais e das caravanas da biodiversidade realizadas por ele e demais membros do seu grupo de trabalho, valorizando o saber regional, a territorialidade, sentimento de pertencimento e pluralidade de culturas de diferentes povos e regiões do Brasil, focando não só na EA e ensino de Biologia, mas também na importância do projeto para a formação de professores.

No quarto encontro do módulo, o Prof. Dr. Rafael Moretto apresentou um panorama geral sobre Biodiversidade, com dados concretos, estimativas e projeções sobre o número de espécies, ressaltando a importância da sistemática filogenética e de estratégias de conservação frente ao desafio do impedimento taxonômico e da crise da biodiversidade, sempre com um olhar para a educação básica e com discussão fundamentada pelos princípios da EA crítica.

No quinto e último encontro desse primeiro módulo, intitulado "Biodiversidade em sala de aula: caminhos para a formação cidadã", as biólogas e pesquisadoras MSc. Anne Caroline de Freitas e MSc. Ana Elisa Montebelli Motta, além de apresentarem as diferentes definições da temática de forma crítica e pautada na legislação, trouxeram exemplos recentes e problematizações acerca da questão ambiental, discutindo como a formação crítica proporcionada pela EA está intimamente relacionada com a formação para a cidadania, apresentando exemplos práticos da aplicação do tema em sala de aula, por meio de sequências didáticas e relatos de experiência.

Tabela 2. Encontros remotos do Módulo II - "Diálogos sobre Sustentabilidade"

\begin{tabular}{|c|c|c|c|}
\hline Datas & Tema & Palestrantes & $\begin{array}{l}\text { Visualizações } \\
\text { no YouTube }\end{array}$ \\
\hline 08/07/2020 & $\begin{array}{l}\text { "Sala de aula, } \\
\text { formação crítica e } \\
\text { responsabilidade } \\
\text { social" }\end{array}$ & $\begin{array}{l}\text { Prof. Dr. Rafael Alberto } \\
\text { Moretto e MSc. Richard } \\
\quad \text { Edgard Moretto }\end{array}$ & 532 \\
\hline $15 / 07 / 2020$ & $\begin{array}{c}\text { “O projeto Nós } \\
\text { Propomos! como } \\
\text { forma de promoção da } \\
\text { cidadania e da } \\
\text { responsabilidade } \\
\text { social" }\end{array}$ & $\begin{array}{c}\text { Prof. }{ }^{\text {a }} \text { Dr. }{ }^{\text {a }} \text { Andrea Coelho } \\
\text { Lastória e MSc. Odair } \\
\text { Ribeiro de Carvalho Filho }\end{array}$ & 792 \\
\hline
\end{tabular}




\begin{tabular}{|c|c|c|c|}
\hline $22 / 07 / 2020$ & $\begin{array}{l}\text { "Como e por quê } \\
\text { abordar os oceanos } \\
\text { nas escolas" }\end{array}$ & $\begin{array}{c}\text { Biol. Vitória Scrich, MSc. } \\
\text { Natalia Grilli e MSc. } \\
\text { Caroline Schio }\end{array}$ & 785 \\
\hline 29/07/2020 & $\begin{array}{l}\text { "Sustentabilidade: um } \\
\text { convite ao ensino } \\
\text { interdisciplinar!" }\end{array}$ & $\begin{array}{c}\text { Dr. }{ }^{\text {a }} \text { Giselle Alves Martins } \\
\text { e Prof. }{ }^{\text {a }} \text { Dr. }{ }^{a} \text { Fernanda da } \\
\text { Rocha Brando }\end{array}$ & 820 \\
\hline $05 / 08 / 2020$ & $\begin{array}{l}\text { "Pensando caminhos } \\
\text { para uma educação } \\
\text { ambiental" }\end{array}$ & $\begin{array}{c}\text { Prof. }{ }^{\text {a }} \text { Dr. }{ }^{\text {a }} \text { Lilian } \\
\text { Catenacci, MSc. Vivian } \\
\text { Catenacci e Biol. Matheus } \\
\text { Mendes }\end{array}$ & 647 \\
\hline
\end{tabular}

O segundo módulo das nossas formações foi intitulado como "Diálogos sobre Sustentabilidade" e constituído por 5 encontros com especialista que estudam sobre ou trabalham com essa temática, em diferentes contextos. A abertura desse módulo foi realizada a partir da palestra "Sala de aula, formação crítica e responsabilidade social" ministrada pelo Prof. Dr. Rafael Alberto Moretto e MSc. Richard Edgard Moretto, os quais trouxeram um panorama histórico do surgimento do termo sustentável e seus desdobramentos e polissemia do conceito, como se deu a preocupação com o meio ambiente pós Revolução Industrial, como o sistema capitalista contribui para um mundo menos sustentável, qual o papel do ser humano em relação ao meio ambiente, a importância dessa temática no contexto educacional e experiências práticas de como abordar educação ambiental na sala de aula, com diferentes faixas etárias, do Ensino Fundamental ao Ensino Superior, explorando os temas integradores, como água, lixo, alimentação, energia, etc.

O segundo encontro desse módulo foi chamado de "O projeto Nós Propomos! como forma de promoção da cidadania e da responsabilidade social", ministrado pela Prof. $^{a}$ Dr. ${ }^{a}$ Andrea Coelho Lastória e MSc. Odair Ribeiro de Carvalho Filho. Os palestrantes apresentaram como surgiu o projeto, quais os princípios objetivos propostos, os passos para realização do projeto Nós Propomos! e um estudo de caso, que fez parte da dissertação de mestrado do Odair, mostrando que é possível um ensino integrado pautado na sustentabilidade, com um exemplo prático de alunos do Ensino Médio participando de uma audiência na câmara municipal, apontando problemas locais levantados por eles e propondo possíveis soluções. 
"Como e por que abordar os oceanos nas escolas" foi o título do nosso terceiro encontro, dirigido pela bióloga Vitória Scrich, contando também com a participação da MSc. Natalia Grilli e da MSc. Caroline Schio, trazendo diferentes tópicos acerca dessa temática, curiosidades, a importância de se estudar sobre os oceanos, como relacionar esse tema com as disciplinas curriculares, qual o impacto do lixo nas águas, qual nosso papel nesse contexto, como podemos realizar atividades sobre esse assunto e as experiências vivenciadas pelas palestrantes em diferentes níveis de ensino, possíveis de serem transpostos e aplicados para a sala de aula.

No quarto encontro, a Prof. ${ }^{a}$ Dr. ${ }^{a}$ Fernanda da Rocha Brando e a Dr. ${ }^{a}$ Giselle Alves Martins nos fizeram um convite para o ensino interdisciplinar através da temática da sustentabilidade, com um panorama histórico sobre o assunto até chegar aos Objetivos do Desenvolvimento Sustentável e a Agenda 2030 da ONU, mostrando o que é a interdisciplinaridade, quais os indicadores dessa estratégia e um estudo de caso aplicando no Ensino Básico, mostrando quais os passos para um ensino de sucesso baseado na temática sustentável.

Para encerrar esse módulo, o biólogo Matheus Mendes, a Prof. ${ }^{\text {a }}$ Dr. ${ }^{\text {a }}$ Lilian Catenacci e a MSc. Vivian Catenacci ministraram o quinto encontro intitulado "Pensando caminhos para uma educação ambiental", trazendo reflexões e experiências vivenciadas em diferentes contextos para um ensino pautado na EA, como a agroecologia, agricultura familiar, o Movimento Sem Terra (MST), brinquedos e brincadeiras e a contação de histórias, por exemplo.

Tabela 3. Encontros remotos do Módulo III - "Diálogos sobre Educação Ambiental"

\begin{tabular}{c|c|c|c}
\hline \multicolumn{1}{c|}{ Datas } & Tema & Palestrantes & $\begin{array}{c}\text { Visualizações } \\
\text { no YouTube }\end{array}$ \\
\hline $\mathbf{1 9 / 0 8 / 2 0 2 0}$ & $\begin{array}{c}\text { "Perspectivas, } \\
\text { princípios e projetos } \\
\text { em Educação } \\
\text { Ambiental" }\end{array}$ & Dr. Antônio Vitor Rosa & 593 \\
\hline $\mathbf{2 6 / 0 8 / 2 0 2 0}$ & $\begin{array}{c}\text { "Educação Ambiental } \\
\text { e identificação de } \\
\text { serpentes } \\
\text { peçonhentas" }\end{array}$ & Biol. Renata Alfredo e & 483 \\
\hline
\end{tabular}




\begin{abstract}
\begin{tabular}{|c|c|c|c|}
\hline $09 / 09 / 2020$ & $\begin{array}{c}\text { “Tem bicho no meu } \\
\text { nicho: jogos } \\
\text { educativos sobre a } \\
\text { interação com animais } \\
\text { em movimento" }\end{array}$ & $\begin{array}{c}\text { Biol. Bruna Lima Ferreira, } \\
\text { MSc. Gabriel Guariglia } \\
\text { Perez e MSc. Anne } \\
\text { Carolina de Freitas }\end{array}$ & 364 \\
\hline $16 / 09 / 2020$ & $\begin{array}{l}\text { "Resíduos sólidos: } \\
\text { entraves e caminhos" }\end{array}$ & $\begin{array}{l}\text { Prof. }^{\text {a }} \text { Dr. }{ }^{\text {a }} \text { Sylmara } \\
\text { Gonçalves Dias }\end{array}$ & 339 \\
\hline $23 / 09 / 2020$ & $\begin{array}{c}\text { "Educação Ambiental } \\
\text { no Brasil e na } \\
\text { Espanha, tem } \\
\text { diferenças?" }\end{array}$ & Prof. ${ }^{\text {a }}$ Dr. ${ }^{\text {a }}$ Gabriela Delord & 333 \\
\hline $30 / 09 / 2020$ & $\begin{array}{l}\text { "A importância das } \\
\text { abelhas e do serviço } \\
\text { de polinização no } \\
\text { ensino de Ciências" }\end{array}$ & Dr. ${ }^{\text {a }}$ Yara Roldão & \\
\hline $21 / 10 / 2020$ & $\begin{array}{l}\text { "Paisagem de som e } \\
\text { imagem" }\end{array}$ & Prof. ${ }^{\text {a Dr. }}$ Jéssica Makino & 207 \\
\hline
\end{tabular}
"Diálogos sobre Educação Ambiental" foi o nome escolhido para o nosso terceiro e mais abrangente módulo de palestras sobre a temática, estruturado em 7 encontros. Nessa etapa, nosso objetivo principal foi reunir experiências práticas sobre diversos temas que tem como eixo central a EA. Para isso, convidamos o Dr. Antônio Vitor Rosa para ministrar o primeiro encontro, intitulado "Perspectivas, princípios e projetos em Educação Ambiental", o qual trouxe um panorama da legislação que rege a EA no Brasil, quais os principais pilares da EA e mostrando a importância da implementação de projetos em EA, principalmente nas escolas.

O segundo encontro foi apresentado pelas biólogas Renata Alfredo e Gabriela Tomé, o qual foi intitulado "Educação Ambiental e identificação de serpentes peçonhentas". As palestrantes abordaram o tema do uso de animais silvestres como instrumento de promoção da EA com detalhes, trazendo especificações técnicas, porém em uma linguagem acessível ao público-alvo do projeto, além de apresentarem recursos que podem ser utilizados para abordar esse tema na sala de aula, como aplicativos, artigos, jogos didáticos e livros que podem ser adaptados para diversos níveis escolares.


"Tem bicho no meu nicho: jogos educativos sobre a interação com animais em movimento" foi o tema do terceiro encontro desse módulo, ministrado pela bióloga Bruna Lima Ferreira, pelo MSc. Gabriel Guariglia Perez e pela MSc. Anne Carolina de Freitas, apresentando como surgiu a ideia de criação do e-book homônimo, quais os principais objetivos desse material, os conceitos que permeiam as entrelinhas e, por fim, a sequência didática com dois jogos didáticos elaborados com o intuito de trabalhar a alfabetização científica e o ensino de ciências por investigação, utilizando a EA como pano de fundo.

O quarto encontro, "Resíduos sólidos: entraves e caminhos", foi apresentado pela Prof. ${ }^{a}$ Dr. ${ }^{a}$ Sylmara Gonçalves Dias, que além da discussão sobre resíduos sólidos e toda a problemática envolvida, trouxe um assunto ainda pouco explorado nas mídias: o microplástico, resíduo majoritariamente gerado pela indústria têxtil, e todo impacto causado pelo consumo desenfreado de roupas, não só em termos de descarte, mas toda cadeia de produção envolvida.

“Educação Ambiental no Brasil e na Espanha, tem diferenças?” foi o título do quinto encontro ministrado pela Prof. ${ }^{a}$ Dr. ${ }^{a}$ Gabriela Delord, brasileira e que atualmente trabalha na Universidad de Sevilla, nos trouxe uma análise das características da EA no Brasil e na Espanha, apontando as principais diferenças, como se deu a inclusão da EA nas escolas e quais os pontos de convergências entre os dois países.

No sexto encontro, a Dr. ${ }^{\text {a } Y a r a ~ R o l d a ̃ o ~ n o s ~ t r o u x e ~ " A ~ i m p o r t a ̂ n c i a ~ d a s ~ a b e l h a s ~ e ~}$ do serviço de polinização no ensino de Ciências", temática que tem sido bastante pontuada nas mídias, uma vez que as abelhas são as principais polinizadoras de flores e frutos. Além disso, Yara apontou os principais mitos e verdades e trouxe um vídeo didático sobre a morfologia das abelhas.

Para encerrar esse módulo e o primeiro ano do projeto, o sétimo encontro foi ministrado pela Prof. a Dr. a Jéssica Makino, intitulado "Paisagem de som e imagem", nos apresentando a EA sob o ponto de vista da arte, descrevendo o que o é paisagem sonora, como surgiu esse conceito, qual sua importância ao longo da história, a questão da poluição sonora e os problemas que ela pode acarretar, além de discutir como o som tem adquirido outros sentidos, acessibilidades e/ou funções com o avanço da tecnologia.

A partir dos resultados apresentados nas tabelas 1, 2 e 3, podemos observar que os vídeos que compõem o módulo I tiveram um total de 3.456 visualizações e uma Recebido em: 18/01/2021 
média de 691 visualizações por encontro. Já o módulo II teve 3.576 acessos, o que resulta numa média de 715 visualizações por encontro. No módulo III, foram 2.580 visualizações e uma média de 369 espectadores por encontro. Esses dados nos mostram que a mudança no formato dos encontros da modalidade presencial para o virtual foi positiva e teve um aceite além das nossas expectativas: na modalidade presencial, o alcance máximo seria de 60 pessoas por encontro, devido à estrutura física, disponibilidade de datas e horários, distância e afins. Nesse sentido, tivemos um alcance quase $1.000 \%$ maior na modalidade à distância, com mais de 9.650 pessoas que assistiram aos encontros remotos, número muito superior ao número máximo que conseguiríamos atingir com os encontros presenciais, que seriam apenas 1.000 pessoas. Isso significa que, em média, a cada encontro, contribuímos com a formação de 500 pessoas a mais do que o inicialmente previsto, já que a média geral supera 565 visualizações por encontro.

Outro dado interessante refere-se ao público-alvo de nosso interesse. Inicialmente, $75 \%$ dos nossos encontros seriam destinados à professores já em atuação na rede municipal e/ou estadual de Ensino e apenas 5 encontros abarcariam um público mais amplo. Ao adaptar para o formato digital e ampliar os meios de divulgação, estendemos a formação para outros grupos, tais como: alunos de Graduação, alunos de Pós-graduação, professores (independente de sua atuação/formação) e outros (pesquisadores, educadores ambientais, comunidade, etc.). A partir do formulário de inscrição, disponibilizado no momento da transmissão do encontro (com uma média de 110 respostas a cada encontro), identificamos que 64\% dos participantes do Módulo I são alunos de Graduação e apenas $19 \%$ são professores formados. No Módulo II, 54\% são alunos de Graduação, enquanto $28 \%$ são professores formados. No Módulo III, nosso público foi composto por $61 \%$ de alunos de Graduação e $25 \%$ de professores formados. Já se analisarmos os dados gerais dos três módulos (Figura 1), do total de espectadores que assistiram aos 17 encontros, mais de 57\% são alunos de Graduação, cerca de $20 \%$ são professores já formados, mais de $16 \%$ são alunos de Pós-graduação e cerca de $6 \%$ corresponde a outros públicos, como educadores ambientais e alunos da Educação Básica, por exemplo.

Apesar de o nosso público-alvo principal ser professores já atuantes, os alunos de Graduação foram os que mais participaram dos encontros, mostrando que nosso 
curso contribuiu para a formação inicial desses estudantes. Os assuntos que foram abordados podem viabilizar futuras discussões em disciplinas de estágios e reflexões sobre a prática pedagógica em espaços não formais, por exemplo, ou mesmo na ação do futuro professor, já que a grande maioria dos alunos é de cursos de licenciatura.

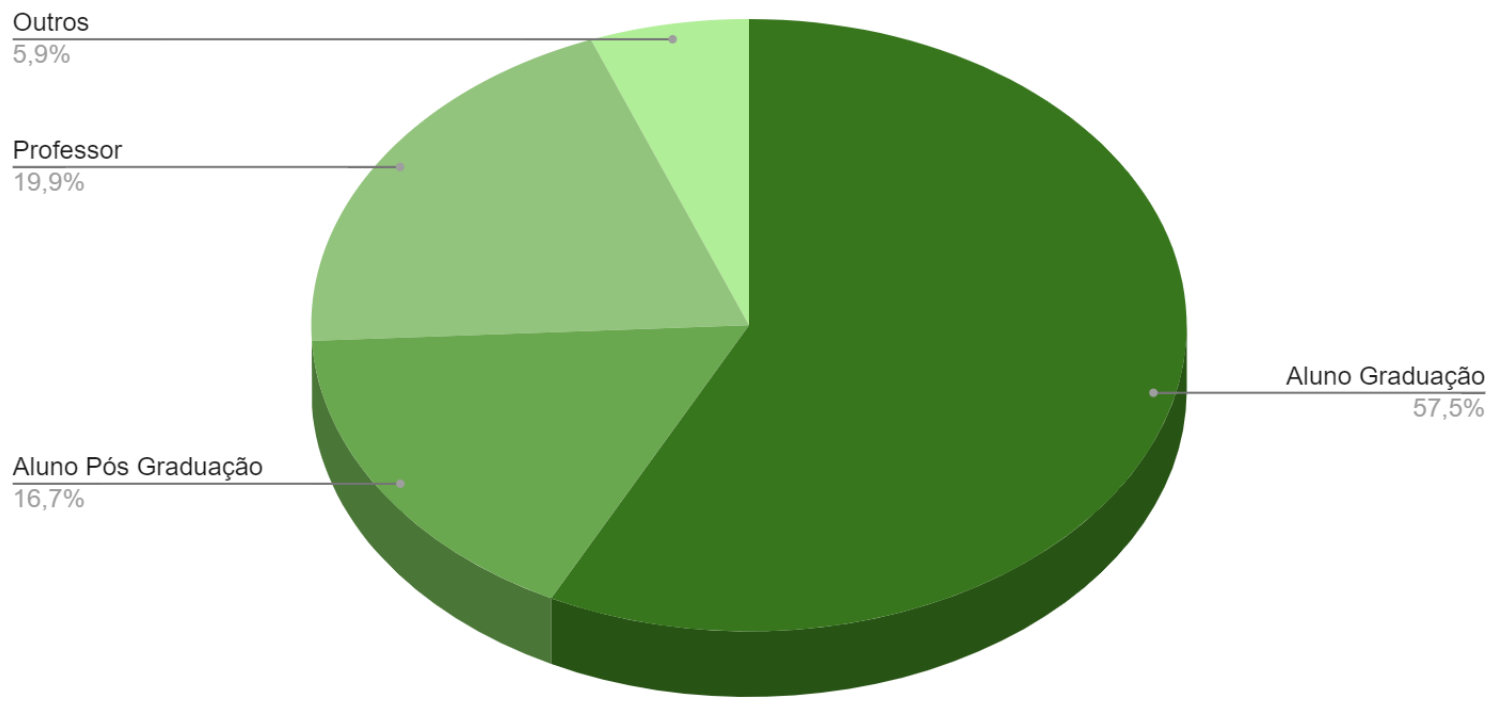

Figura 1 - Gráfico sintetizando a porcentagem total de participantes de cada categoria que responderam aos formulários de presença dos 17 encontros do projeto.

Outro aspecto bastante positivo foi a possibilidade de trabalhar a formação inicial e continuada dos professores de maneira integrada ao longo dos 17 encontros, em consonância com as novas diretrizes curriculares nacionais para formação de professores da Educação Básica (DOURADO, 2015; HONÓRIO et al., 2017). Pudemos observar trocas de experiências e ideias entre professores já atuantes e alunos em formação, enriquecendo a discussão sobre cada um dos temas e trazendo contribuições e visões a partir de diferentes perspectivas, experiências e concepções prévias. Como defendido por Machado e Boruchovitch (2015), ao se trabalhar a formação inicial e continuada de professores de maneira articulada, viabiliza-se as práticas autorreflexivas por parte de todos os envolvidos no processo, favorecendo o processo de ensinoaprendizagem. 
Tais interações podem ser observadas pelo elevado número de comentários ao vivo em cada uma das lives, com grande interação entre o público participante, que além de perguntas sobre a temática apresentada para os respectivos palestrantes, também trocavam relatos de experiências entre si, dicas de leitura, materiais e até mesmo propostas de parceria entre professores e instituições de ensino.

Por meio do presente trabalho, ressaltamos a importância da temática ambiental, não só na formação inicial e continuada de professores, mas também na prática pedagógica desse docente, independente de qual nível de ensino seja sua atuação. Ao oportunizar discussões sobre EA em sala de aula, o professor deverá propiciar que os estudantes sejam instigados por meio de questões provocativas que despertem a consciência ecológica, o senso crítico e a mudança atitudinal, um dos pilares da EA e todo seu potencial político-formativo (PEREIRA; AMARAL, 2020), que permeia o cerne da formação cidadã. Nesse sentido, conseguimos promover, por exemplo, discussões sobre controvérsias sócio-científicas com os nossos alunos, que resultam não só na sensibilização quanto à importância da temática ambiental, mas também instigando ações sócio-políticas e de cidadania (REIS, 2013).

Em todos os encontros, foram abordados os princípios da EA crítica (CARVALHO, 2001; GUIMARÃES, 2004; TOZONI-REIS, 2008), temáticas, situações-problema e metodologias possíveis de serem transpostas para o cotidiano escolar e adaptadas para as diferentes faixas etárias, contextualizada e adaptada à realidade interdisciplinar (FAZENDA, 2008), vinculada aos temas ambientais e globais.

Diferentes perspectivas têm sido utilizadas na formação (inicial e continuada) de professores em EA, levando-se a questionar o enfoque dado para o desenvolvimento de conhecimentos, habilidades, valores e ações efetivas, necessárias à inserção da dimensão ambiental nos currículos de formação de professores. Nesse sentido, destacamos que o processo de formação docente em EA não deve se reduzir ao treinamento, capacitação, nem à transmissão de conhecimentos. Ele deve ser, acima de tudo, uma reconstrução de valores éticos, da práxis refletida, um processo de reflexão crítica (MARTINS; SCHNETZLER, 2018).

\section{CONSIDERAÇÕES FINAIS}


Edição Especial: I SSAPEC - Simpósio Sul-Americano de Pesquisa em Ensino de Ciências

ISSN: 2595- $4520 \quad$ Vol. 4, n. 3. 2021

Sabemos e lamentamos que muitas interações e discussões são minimizadas e/ou perdidas em cursos de modalidade à distância, porém, não podemos negar que a Internet nos permite romper com as limitações físicas e temporais do ensino presencial. Nosso curso tinha como objetivo a formação inicial e continuada do público-alvo (professores já formados e alunos de Graduação) e nossas expectativas foram superadas, uma vez que o alcance foi muito superior do que havíamos previsto. Além disso, pudemos proporcionar encontros com palestrantes de diferentes estados, além de estabelecer contato com espectadores do país inteiro e até mesmo do exterior, contribuindo diretamente com a divulgação e promoção da EA.

Alguns dos resultados não conseguimos dimensionar nesse momento, como o número de visualizações dos vídeos com o passar do tempo ou a utilização do que foi aprendido nos encontros em momentos de formação e discussão em aulas e reuniões pedagógicas, por exemplo. Em estudos futuros, pretendemos investigar o efeito direto dos cursos de formação na prática docente dos participantes dos encontros, trazendo relatos e práticas que foram transpostas e aplicadas em sala de aula, em diferentes contextos e com diferentes faixas etárias.

Esse trabalho buscou proporcionar conhecimentos, experiências e parcerias em meio a um momento de desafios e desesperança, não somente em questões ambientais, mas também de humanidade. Além de tudo, ser uma rede de apoio aos professores que se sentem desamparados e inseguros com o cenário atual da Educação brasileira, mostrando a importância de lutarmos por uma educação de qualidade para nossos alunos.

\section{AGRADECIMENTOS}

Os autores agradecem a todos os palestrantes que contribuíram com o projeto e participaram voluntariamente das lives, ao público que nos acompanhou ao longo de todos os encontros, ao Departamento de Educação, Informação e Comunicação da Faculdade de Filosofia, Ciências e Letras de Ribeirão Preto, Universidade de São Paulo pelo apoio institucional, à Pró-reitoria de Graduação da USP pelo fomento do projeto, por meio do Programa Unificado de Bolsas, e aos pareceristas anônimo, pela leitura crítica e sugestões no manuscrito que deu origem a esse artigo. 


\section{REFERÊNCIAS}

BRASIL. Parâmetros Curriculares Nacionais (PCNs). Brasília, MEC/SEF, 1999.

BRASIL. Base Nacional Comum Curricular: educação é a base. Brasília: Ministério da Educação, 2018.

CARVALHO, I. C. M. A invenção ecológica: narrativas e trajetórias da educação ambiental. Porto Alegre: Ed. UFRGS, 2001.

DOURADO, L. F. Diretrizes curriculares nacionais para a formação inicial e continuada dos profissionais do magistério da educação básica: concepções e desafios. Educação \& Sociedade, v. 36, n. 131, p. 299-324, 2015. Disponível em: https://www.scielo.br /scielo.php?pid=S0101-73302015000200299\&script=sci_abstract\&tlng=pt. Acesso em 06 jan. 2021.

FAZENDA, I. C. A. Interdisciplinaridade- Transdisciplinaridade. In: PERES, E.; TRAVERSINI, C.; EGGERT, E. \& BONIM, I. (Orgs.). Trajetórias e processos de ensinar e aprender: sujeitos, currículo e cultura. 1. ed. Porto Alegre: Edipucrs, p. 35 $58,2008$.

FREIRE, P. A Educação na Cidade. São Paulo: Cortez, 1991.

GUIMARÃES, M. A formação de educadores ambientais. Campinas: Papirus, 2004. HONÓRIO, M. G., LOPES, M. S. L., LEAL, F. L. S., HONÓRIO, T. C. T., \& SANTOS, V. A. As novas diretrizes curriculares nacionais para formação inicial e continuada de professores da educação básica: entre recorrências e novas inquietações.

Revista Ibero-Americana De Estudos Em Educação, v. 12, n.3, p. 1736-1755, 2017.

Disponível em: https://periodicos.fclar.unesp.br/iberoamericana/article/view/8532. Acesso em 27 set. 2020.

IMBERNÓN, F. Formação continuada de professores. Porto Alegre: Artmed, 2010. LASTÓRIA, A. C., ASSOLINI, F. E. P. A aprendizagem, a formação e a experiência como elementos centrais dos processos educativos de professores. In: ASSOLINI, F. E. P., LASTÓRIA, A. C. Formação continuada de professores: processos formativos e investigativos. São Carlos, Editora Compacta, 2010.

MACHADO, A. C. T. A \& BORUCHOVITCH, E. As práticas autorreflexivas em cursos de formação inicial e continuada para professores. Psicologia, Ensino \& Formação, v. 06, n. 2, p. 54-67, 2015. Disponível em: http://pepsic.bvsalud. org/scielo.php?script=sci_arttext\&pid=S2177-20612015000200005. Acesso em 26 set. 2020. 
MARTINS, J. P. A., SCHNETZLER, R. P. Formação de professores em educação ambiental crítica centrada na investigação-ação e na parceria colaborativa. Ciênc. Educ., Bauru, v. 24, n. 3, p. 581-598, 2018. Disponível em: http://www.scielo.br /scielo.php?script=sci_arttext\&pid=S1516-73132018000300581\&lng=en\&nrm=iso. Acesso em 25 set. 2020.

MENDES, K. M. A pesquisa na formação continuada de professores: possibilidades e limites. Revista Triângulo, Uberaba, v. 6, n. 1, p. 22-30, 2013. Disponível em: http://seer.uftm.edu.br/revistaeletronica/index.php/revistatriangulo/article/view/497. Acesso em: 16 set. 2020.

MORETTO, R. A. Interdisciplinaridade e responsabilidade social por meio da Educação Ambiental. In: ANDRADE, J. J.; ABREU, D.G., GASPARINI, A. P. S. Experiências Compartilhadas: diálogos sobre a formação docente e ensino de ciências. $1^{\mathrm{a}} \mathrm{ed}$. Ribeirão Preto, Editora Herograf, 2018.

NOGUEIRA, C. M. I; PAVANELLO, R. M; OLIVEIRA, L. A. Uma experiência de formação continuada de professores licenciados sobre a matemática dos anos iniciais do ensino fundamental. Revista Paranaense de Educação Matemática, Campo Mourão, v. 3, n. 4, p. 138-160, 2014. Disponível em: http://www.fecilcam.br/revista/ index.php/rpem/article/view/907. Acesso em 10 set. 2020.

NÓVOA, A; FINGER, M. (Orgs.). O método (auto)biográfico e a formação. Natal: EDUFRN; São Paulo: Paulus, 2010.

PEREIRA, V. A; AMARAL, M. J. Novas exigências a Educação Ambiental no contexto pós-COVID-19: desafios a redefinição do Projeto Pedagógico. Revista

Insignare Scientia, vol. 5, n. 5, p. 312-327, 2020. Disponível em: https://periodicos.uffs.edu.br/index.php/RIS/article/view/11906/7586. Acesso em 12 fev. 2021.

REIS, P. Da discussão à ação sociopolítica sobre controvérsias sócio-científicas: uma questão de cidadania. Ensino de Ciências e Tecnologia em Revista, v. 03, n. 1, p. 110, 2013. Disponível em: https://www.researchgate.net/publication/257132888_DA_ DISCUSSAO_A_ACAO_SOCIOPOLITICA_SOBRE_CONTROVERSIAS_SOCIOCIENTIFICAS_UMA_QUESTAO_DE_CIDADANIA_FROM_THE_DISCUSSION_T O_THE_SOCIOPOLITICAL_ACTION_ABOUT_SOCIO_SCIENTIFIC_ISSUES_A_ MATTER_OF_CITIZENSHIP. Acesso em 06 set. 2020.

SANTANA, A. C. M; ROTHEN, J. C. A avaliação externa das escolas e a formação continuada de professores: o caso paulista. Revista Diálogo Educacional, Curitiba, v. 
Edição Especial: I SSAPEC - Simpósio Sul-Americano de Pesquisa em Ensino de Ciências

15, n. 44, p. 89-110, 2015. Disponível em: https://periodicos.pucpr.br/index.php/ dialogoeducacional/article/view/5056. Acesso em: 05 jan. 2021.

TARDIF, M. Saberes docentes e formação profissional. Petrópolis, Editora Vozes, 2002.

TOZONI-REIS, M. F. C. Metodologias aplicadas à educação ambiental. Curitiba: IESD, Brasil, 2008. 